D.O.I: $10.3895 / S 1808-04482013000100001$

\title{
INOVAÇÃO EM SERVIÇOS: ANÁLISE DO CASO DE UMA EMPRESA DE MÉDIO PORTE NO NORDESTE BRASILEIRO
}

\section{INNOVATION IN SERVICES: ANALYSIS OF THE CASE OF A MEDIUM SIZED ENTERPRISE IN NORTHEAST BRAZIL}

\author{
Vivianne Pereira Salas Roldan ${ }^{1}$; Augusto Cézar de Aquino Cabral ${ }^{2}$; José Carlos Lázaro da Silva \\ Filho $^{3}$; Sandra Maria dos Santos ${ }^{4}$; Maria Naiula Monteiro Pessoa ${ }^{5}$ \\ ${ }^{1}$ Centro de Treinamento e Desenvolvimento - CETREDE/UFC - Fortaleza - Brasil \\ vsalasroldan@gmail.com \\ ${ }^{2}$ Universidade Federal do Ceará - UFC - Fortaleza - Brasil \\ cabral@ufc.br \\ ${ }^{3}$ Universidade Federal do Ceará - UFC - Fortaleza - Brasil \\ silvafilhode@yahoo.com.br \\ ${ }^{4}$ Universidade Federal do Ceará - UFC - Fortaleza - Brasil \\ smsantosufc@gmail.com \\ ${ }^{5}$ Universidade Federal do Ceará - UFC - Fortaleza - Brasil \\ naiula@ufc.br
}

\begin{abstract}
Resumo
Este artigo procurou caracterizar o processo de inovação em uma empresa de médio porte de serviço, no Nordeste brasileiro, identificando, a partir dessa análise, a existência de fatores internos favoráveis à inovação, as possíveis barreiras à atividade inovativa, e o tipo de inovação implementado. Após uma revisão teórica sobre a inovação em serviços, os fatores favoráveis à inovação e suas barreiras, os autores realizaram um estudo exploratório, qualitativo, utilizando o método de estudo de caso. A pesquisa foi realizada numa empresa de médio porte de instalações industriais, situada no município de Fortaleza, Estado do Ceará, Brasil. Nos resultados, constatouse a predominância da inovação organizacional. Como principais barreiras à atividade inovativa, identificou-se: 1) questões de natureza sistêmica: falta de um processo de inovação sistemático, inexistência da análise de cenários, perdas de possibilidades de parcerias com outras empresas e instituições de pesquisa, e dificuldade para captação de clientes; 2) gestão de pessoas: falta de reconhecimento do fator humano no processo de inovação, uma vez que a cultura organizacional não está voltada para a inovação; perda de pessoal qualificado. Como fatores internos favoráveis à inovação foram identificados: apoio da alta administração, estrutura organizacional simples $e$ flexível, espaço de trabalho favorável ao clima criativo, competência técnica dos colaboradores, processos de seleção alinhados ao fomento de criatividade, capacidade de aprender e diversidade de perfis, e existência de mecanismos formais e informais para fomentar o aprendizado com clientes e fornecedores. A cultura da inovação não está consolidada, mas está em vias de ser implementada, pois a empresa está ligada a uma associação de desenvolvimento da inovação (GESTINNO).
\end{abstract}

Palavras-chave: Inovação organizacional; fatores facilitadores da inovação; barreiras à inovação. 


\section{Introdução}

Dentro da perspectiva econômica evolucionária, a inovação tem sido considerada um fator chave para o desenvolvimento econômico e competitividade das nações, sendo tratada como vantagem competitiva essencial das empresas. Sua importância tem crescido, tendo em vista o aumento da competição global, a redução do ciclo de vida dos produtos, a elevação da capacidade tecnológica das empresas e as rápidas mudanças das demandas de consumo (SCHUMPETER, 1988; FREEMAN, SOETE, 2008; ) . O sucesso de pequenas e médias empresas em aumentar a sua competitividade no mercado tem sido, portanto, cada vez mais dependente da forma como elas têm lidado com essa questão (MADRID-GUIJARRO et al, 2009).

Dados do PINTEC demonstram um baixo esforço inovador das empresas nacionais, embora venha aumentando. O percentual de crescimento do número de empresas que realizaram inovações (relativo ao total de empresas), no período de 2003 a 2005, ainda é baixo, apenas 3,2\% em produto novo e $1,7 \%$ em processo. Práticas impulsionadoras da inovação, como as parcerias com as universidades e instituições de pesquisa, são ainda muito pouco aplicadas pelas firmas brasileiras. Contudo, é crescente o número de empresas que vem reconhecendo a importância dessas práticas (PUFFAL; COSTA, 2008).

No Ceará, a promoção do desenvolvimento do Estado em termos de conhecimento e inovação tem sido coordenado pelo órgão SECITECE - Secretaria da Ciência, Tecnologia e Educação Superior do Estado do Ceará criado em 1995, e que tem o papel de "coordenar e viabilizar o fomento, a difusão e a aplicação do conhecimento científico e tecnológico no Ceará" (SECITECE, 2010, a). Dentre as atividades do referido órgão, estão ações e programas como: apoio à incubação de empresas, estruturação competitiva de arranjos produtivos locais e serviços tecnológicos, apoio a núcleos de inovação tecnológica, captação e gestão de projetos inovadores; encontros, fóruns e seminários relacionados à inovação (SECITECE, 2010, b). Dados da PINTEC, do período de 2006 a 2008, demonstram que das 2.085 firmas cearenses pesquisadas (indústrias extrativas e de transformação), 40,3\% realizam inovação de produto e processo; $44 \%$ realizam apenas inovações organizacionais e/ou de marketing; e apenas $0,03 \%$ realizam apenas projetos incompletos e/ou abandonados (IBGE, 2010).

Tendo em vista a importância da inovação para a competitividade das empresas e o reconhecimento crescente por essas instituições para a adoção de práticas inovativas, inúmeros pesquisadores têm procurado investigar os fatores favoráveis e desfavoráveis à inovação nas organizações. Contudo, a ênfase da maior parte dos estudos em inovação tem sido as inovações tecnológicas, sendo poucas as pesquisas que tem focado as inovações organizacionais. Também as empresas de serviços receberam atenção relativamente pequena dos estudiosos da inovação, 
principalmente até o final do século $\mathrm{XX}$, por serem vistas mais como usuários de tecnologia, do que verdadeiros inovadores (TETHER; TAJAR, 2008).

Considerando-se as perspectivas individual e contextual do estudo e prática de inovação destacados por Bessant e Tidd (2009), este trabalho procura responder ao seguinte problema de pesquisa: O processo de inovação nas organizações prestadoras de serviços está mais relacionado à inovação tecnológica ou gerencial?

Para responder a essa problemática, o estudo teve como objetivo geral caraterizar o processo de inovação em uma empresa de médio porte cearense que presta serviços especializados de instalações e montagens industriais. Como objetivos específicos, pretendeu: 1) Identificar os fatores internos favoráveis à inovação; 2) Analisar as possíveis barreiras internas e externas à atividade inovativa; 3) Verificar o tipo de inovação implementado pela organização.

Pretende-se contribuir para uma melhor compreensão dos desafios enfrentados pelas pequenas e médias empresas para fomentar a inovação, no Nordeste Brasileiro, com foco no setor de serviços.

\section{Referencial teórico}

\subsection{Inovação em Serviços}

A inovação é, nas palavras de Peters (2008), um fenômeno complexo, tendo ganhado na literatura acadêmica diversas definições. Entre estas, o que existe de comum é a idéia da introdução de algo novo conforme proposto pelos clássicos como Schumpeter(1988) ou Freeman e Soete (2008). Ressalta Brem (2008) que a maior parte das definições foca apenas a implementação de novos produtos e processos, contra alguns autores que realizam uma abordagem mais ampla, onde incluem mudanças em métodos de marketing, contratos legais, atividades sociais, entre outros.

Schumpeter (1988) apresenta um dos primeiros conceitos, afirmando que a inovação é simplesmente fazer coisas novas ou fazer as coisas que já estão sendo feitas de outra forma. Este conceito é embasado na compreensão da inovação por Schumpeter (1988) como sendo um dos seguintes eventos: introdução de um novo produto ou mudança qualitativa em um produto já existente; implementação de um novo método de produção ou de transporte; abertura de um novo mercado; desenvolvimento de novas fontes de matérias-primas e outros insumos; e mudanças na organização industrial.

Em abordagem mais recente, Johnson (2001) aponta as seguintes formas de inovação: criação de novos produtos e serviços, geralmente via departamento de pesquisa e desenvolvimento; nova forma de usar um produto ou serviço estabelecido; mudanças na exploração do mercado; inovação logística e operacional; inovação no modelo de negócio. 
De acordo com Tether e Tajar (2008), recentemente tem crescido o interesse dos pesquisadores de inovação em estudar o setor de serviços, destacando-se dentre os estudiosos: Evangelista (2000) que abordou sobre as mudanças tecnológicas em serviços; autores como Gallouj e Weinstein (1997); Gallouj (2002); Sundbo (1997, 1998); Sundbo e Gallouj (2001); Djellal e Gallouj (2001); e Van der Aa e Elfring (2002), que enfatizaram o caráter distinto do setor de serviços, defendendo a necessidade de ampliar a compreensão da inovação no setor para além das abordagens voltadas para as questões tecnológicas; e atualmente, pesquisadores como Drejer (2004), Hipp e Grupp (2005), Djellal e Gallouj (2005), e Vries (2006), que tem desenvolvido uma abordagem em forma de síntese, focando a inovação aplicável a todas as atividades econômicas, mas que não privilegia apenas determinadas formas de inovação, em detrimento de outras como a inovação organizacional.

Busca-se uma abordagem mais ampla da inovação para melhor compreender sua ocorrência nos serviços, crescendo entre os pesquisadores o consenso de que é distinta a forma como as empresas industriais e de serviço inovam. O próprio Manual de Oslo, em sua terceira edição, reconhece que a inovação no setor de serviços se diferencia em muito da que ocorre em setores de fabricação, sendo geralmente incremental, menos tecnológica e pouco organizada formalmente (TETHER; TAJAR, 2008).

Conforme Gadrey e Gallouj (1994) duas formas básicas de inovação no setor de serviços: 1) buscar a maneira mais eficiente de solucionar um problema, o que seria equivalente à inovação de processos; 2) procurar novas soluções de problemas, ou serviços novos para o mercado, ou para as empresas, o que seria equivalente à inovação de produtos. A essas duas formas básicas, conforme Tether e Tajar (2008), a $3^{\text {a }}$ edição do Manual de Oslo acrescenta a denominada inovação organizacional para mensurar a inovação nas empresas, incluindo as de serviços. Essa terceira edição define a inovação organizacional como "a implementação de um novo método organizacional nas práticas de negócios da empresa, organização do trabalho ou nas relações externas"(OECD, 2005, p. 177). Autores como Van der Aa e Elfring (2002) afirmam que a inovação organizacional possuem maior importância no setor de serviços, devido sua forte ênfase no desenvolvimento e aplicação de fórmulas organizacionais. Conforme Tether e Tajar (2008), o Manual de Oslo também explica que a inovação organizacional se diferencia das demais mudanças organizacionais por consistir na implantação de método de organização outrora não usado na empresa e ser resultado de suas decisões estratégicas.

\subsection{Inovação Organizacional}

A terceira edição do Manual de Oslo define a inovação organizacional como "a implementação de um novo método organizacional nas práticas de negócios da empresa, 
organização do trabalho ou nas relações externas"(OECD, 2005, p. 177). De acordo com Tether e Tajar (2008), podem ser identificados três correntes da literatura sobre inovação organizacional: a primeira é a teoria do design organizacional que relaciona as formas estruturais da organização e sua propensão para inovar, preocupando-se não com a inovação em si, mas em identificar quais características da empresa estão associadas à inovação; a segunda corrente é representada pelas teorias de cognição e aprendizagem organizacional, procurando compreender como são desenvolvidas as idéias para solucionar problemas na empresa; a terceira corrente engloba as pesquisas sobre as mudanças e processos de adaptação organizacionais, onde se busca identificar também os processos relacionados à criação de novas formas organizacionais.

Seguindo abordagem de Wengel et al (2000), pode-se classificar a inovação organizacional em dois tipos: inovações estruturais e inovações de gestão. A inovação estrutural tem como foco o arranjo organizacional da empresa e sua divisão de trabalho, enquanto a inovação gerencial foca as operações e procedimentos específicos utilizados pela empresa para organizar suas atividades. Também, conforme o mesmo autor, as inovações organizacionais podem ocorrer em três níveis: 1) nível de subunidade, onde as inovações ocorrem em determinado departamento ou função; 2) nível organizacional, onde a inovação se aplica a toda empresa; e 3) nível supra-organizacional, cujas inovações se referem aos impactos das relações da empresa com o meio ambiente, principalmente com outras organizações.

Estudiosos como Hamel (2006) argumentam que as inovações gerenciais podem superar as inovações tradicionais de processos e produtos, ocorrendo em conjunção com as inovações tecnológicas. O uso de novas tecnologias geralmente trazem mudanças complementares na administração, assim como nas competências e estrutura organizacional (TETHER; TAJAR, 2008).

Nos tópicos seguintes são apresentados a revisão de literatura sobre os fatores organizacionais internos favoráveis à inovação, e as barreiras à inovação.

\subsection{Fatores internos favoráveis à inovação}

De acordo com Bessant e Tidd (2009, p.60), o estudo da inovação e do empreendedorismo pode ser abordados a partir de três diferentes perspectivas: "Pessoal ou individual, que enfatiza o papel da criatividade; Coletiva ou social, que enfatiza a contribuição de equipes e grupos; Contextual, que focaliza as estruturas, o ambiente, os processos e as ferramentas".

Fazendo uso da perspectiva contextual e individual, foram destacados da literatura do emprendedorismo corporativo, inovação, gestão de pessoas, e gestão de conhecimento, os fatores corporativos favoráveis à inovação, descritos no Quadro 1. Na pespectiva individual, o foco foi o papel de determinados indivíduos para a inovação. 
Quadro 1 - Fatores corporativos favoráveis à inovação

\begin{tabular}{|c|c|c|}
\hline FATORES & DESCRIÇÃO & AUTORES \\
\hline $\begin{array}{l}\text { 1.Papel da alta } \\
\text { administração }\end{array}$ & $\begin{array}{l}\text { O comprometimento da alta gestão e suas lideranças, } \\
\text { devendo existir entre eles, um senso de propósito claramente } \\
\text { compartilhado e articulado. }\end{array}$ & $\begin{array}{l}\text { Kuratko et al (1990), Hornsby et } \\
\text { al (1993), Christensen (2005), } \\
\text { Terra (2005), Antoncic (2007), } \\
\text { Tidd, Bessant e Pavit (2008), } \\
\text { Prahalad e Krisnan (2008), e } \\
\text { Alpkan et al (2010) }\end{array}$ \\
\hline $\begin{array}{c}\text { 2.Estrutura } \\
\text { organizacional }\end{array}$ & $\begin{array}{l}\text { Necessidade de um nível de descentralização, autonomia, } \\
\text { flexibilidade de políticas e mecanismos de controle } \\
\text { favoráveis à inovação. }\end{array}$ & $\begin{array}{l}\text { Kuratko et al (1990), Hornsby et } \\
\text { al (1993), Christensen (2005), } \\
\text { Antoncic (2007), Tidd, Bessant } \\
\text { e Pavit (2008), Bessant e Tidd } \\
\text { (2009) e Alpkan et al (2010) }\end{array}$ \\
\hline $\begin{array}{l}\text { 3. Indivíduos- } \\
\text { chave }\end{array}$ & $\begin{array}{l}\text { Presença de indivíduos facilitadores da inovação: os } \\
\text { defensores técnicos, com competência técnica para dar } \\
\text { suporte ao desenvolvimento das idéias inovadoras, capazes } \\
\text { de compreender a tecnologia nova a ser adotada; os } \\
\text { patrocinadores organizacionais, dotados de poder e } \\
\text { influência na organização para levar à frente as idéias } \\
\text { inovadoras; e os gatekeepers tecnológicos, indivíduos que } \\
\text { coletam informações de várias fontes e que as repassa para } \\
\text { as pessoas mais capacitadas ou interessadas em usá-las. }\end{array}$ & Tidd, Bessant e Pavit (2008) \\
\hline \multirow{4}{*}{$\begin{array}{l}\text { 4. Gestão de } \\
\text { recursos humanos }\end{array}$} & $\begin{array}{l}\text { a)sistemas de recompensa; b) práticas de } \\
\text { compensação/recompensa de incentivo baseado no grupo; c) } \\
\text { processo de seleção focado em atrair as melhores pessoas } \\
\text { em termos de potencial inerente. }\end{array}$ & $\begin{array}{l}\text { Kuratko et al (1990); Hornsby et } \\
\text { al (1993); Barbieri et al (2004); } \\
\text { Christensen (2005); Tidd, } \\
\text { Bessant e Pavit (2008); Lopes- } \\
\text { Cabrales et al, 2009) }\end{array}$ \\
\hline & $\begin{array}{l}\text { Contratação e promoção de pessoas essencialmente } \\
\text { diferentes do padrão (diversidade de perfis) }\end{array}$ & Terra (2005) \\
\hline & $\begin{array}{l}\text { a) processo de seleção que avalia a capacidade de colaborar } \\
\text { e trabalhar em equipe; b) realização de atividades que } \\
\text { favoreçam a sociabilização entre os trabalhadores; c) } \\
\text { atividades de treinamento com foco na construção de } \\
\text { equipes e relações interpessoais; d) avaliações baseadas no } \\
\text { desempenho da equipe; e) avaliações com base na } \\
\text { capacidade dos funcionários em trabalhar com os outros; f) } \\
\text { práticas como gestão de carreira, mentoring e coaching; g) } \\
\text { avaliações de desempenho com feedback aos indivíduos, } \\
\text { promovendo a autonomia; h) avaliações com base na } \\
\text { capacidade dos funcionários em trabalhar com os outros; i) } \\
\text { atividades de treinamento com foco na construção de } \\
\text { equipes e relações interpessoais; j) desenvolvimento de } \\
\text { carreira. }\end{array}$ & Lopes-Cabrales et al (2009) \\
\hline & $\begin{array}{l}\text { a) processo de contratação fundamentado nas competências } \\
\text { essenciais necessárias ao negócio; b) a evolução dos salários } \\
\text { está associada, principalmente, à aquisição de competências } \\
\text { e não ao cargo ocupado; c) compartilhamento do } \\
\text { conhecimento como um dos critérios da avaliação de } \\
\text { desempenho; d) investimento elevado no treinamento e } \\
\text { desenvolvimento profissional dos empregados; e) adoção de } \\
\text { programas formais de gestão de talentos; f) desenvolvimento } \\
\text { de carreira. }\end{array}$ & $\operatorname{Terra}(2005)$ \\
\hline $\begin{array}{l}\text { 5. Sistema de } \\
\text { comunicação e } \\
\text { informação }\end{array}$ & $\begin{array}{l}\text { Ter um sistema de comunicação e informação bem } \\
\text { estruturado e integrado, que viabilize o amplo acesso à } \\
\text { informação, assim como seu uso estratégico. }\end{array}$ & $\begin{array}{l}\text { Barbieri et al (2004), Mendel } \\
\text { (2004), Lopes-Cabrales et al } \\
\text { (2009), Christensen (2005), } \\
\text { Antoncic (2007), Terra (2005), e } \\
\text { Tidd, Bessant e Pavitt (2008). }\end{array}$ \\
\hline $\begin{array}{l}\text { 6. Aprendizagem } \\
\text { com o ambiente }\end{array}$ & $\begin{array}{l}\text { Organização atenta à necessidade de aprendizado, que deve } \\
\text { ser estendida para além dos limites da empresa, ou seja, com } \\
\text { clientes, fornecedores, institutos de pesquisa, universidades, } \\
\text { e demais stakeholders. }\end{array}$ & $\begin{array}{l}\text { Mendel (2004), Terra (2005) e } \\
\text { Tidd, Bessant e Pavitt (2008) }\end{array}$ \\
\hline
\end{tabular}

Fonte: Pesquisa Bibliográfica (2011). 


\subsection{Barreiras à inovação}

Em uma pesquisa realizada pela Strategos (uma empresa global de inovação estratégica), junto a mais de 550 empresas de grande porte, os entrevistados apontaram como principais obstáculos à inovação: 1) foco no curto prazo; 2) falta de tempo, recursos ou pessoal; 3) liderança que deseja um retorno mais rápido do que a realidade permite; 4) falta de incentivos de gestão para recompensar a inovação; 5) falta de um processo de inovação sistemático; 6) a crença de que a inovação é arriscada (LOEWE; DOMINIQUINI, 2006).

Discutindo suas tentativas de superar esses obstáculos, foi observado que os entrevistados estavam lidando com esses problemas de forma fragmentada e não sistêmica. Por exemplo, a empresa procura implementar um processo de inovação no local, mas não recompensa os inovadores e os líderes pelo sucesso alcançado com as inovações; procura fazer um plano de incentivo para a gestão inovadora, mas não consegue fazer os gestores se concentrarem na redução de custos no último exercício; se há escassez de idéias, aplica apenas a tática comum de sessões de geração de idéias; se a falta de recursos é o problema, nomeia uma equipe para levar a inovação pra frente; e assim por diante (LOEWE; DOMINIQUINI, 2006).

Em sua atividade na empresa Strategos, Loewe e Dominiquini (2006) observaram que para ser uma empresa inovadora de sucesso, é necessário enfrentar esses obstáculos de forma sistêmica, cuja abordagem deverá focar quatro causas interrelacionadas e subjacentes de ineficácia da inovação: 1) liderança e organização (líderes visionários e organização alinhada em torno de uma definição comum de inovação); 2) processos e ferramentas (abordagem sistemática e ferramentas de suporte para habilitar a elaboração e geração de idéias, gestão de canais e portfólio); pessoas e competências (uma massa crítica de pessoas em toda a organização, sobre abordagens e ferramentas de inovação); cultura e valores (cultura aberta, colaborativa e incentivos que recompensem a mudança de status quo).

Madrid-Guijarro, Garcia e Van Auken (2009) analisaram as barreiras à inovação junto a uma amostra de 294 gestores de pequenas e médias empresas na Espanha, examinando a relação do produto, processo e gestão da inovação, com esses obstáculos. Na revisão da literatura realizada para a pesquisa, os autores levantaram as seguintes barreiras à inovação:

a) Barreiras internas: custos elevados; dificuldade para controlar o custo da inovação; risco excessivo; perda de pessoal qualificado; dificuldade de acesso a recursos financeiros; problemas para manter pessoal qualificado; falta de treinamento de funcionários internos; resistência dos empregados à mudança. 
b) Barreiras externas: suporte insuficiente do governo; turbulência econômica; perda de informação de mercado; perdas da infraestrutura regional; perda de informação sobre tecnologias; perdas de possibilidades com parceiros externos.

O estudo demonstrou que as variáveis produto, processo e gestão da inovação, são afetadas de formas diferentes pelos obstáculos. Processo e gestão da inovação são afetados negativamente por barreiras internas (como recursos humanos e fraca posição financeira), e positivamente afetados por barreiras provenientes do ambiente. O fator de risco associado a custos e problemas de financiamento impacta de forma significativa apenas na gestão da inovação. Verificou-se no geral, que barreiras mais significativas estão associados a custos, e menos significativas estão associados à resistência do gerente ou trabalhador. Embora os gestores pesquisados não tenham considerado os recursos humanos como uma barreira relevante, a pesquisa revela que esse fator tem um impacto negativo sobre a inovação das empresas. O estudo demonstra que as pequenas empresas são mais afetadas do que as maiores pelas barreiras associadas ao custo.

Com relação às barreiras relacionadas à inovação enfrentadas pelas firmas brasileiras, dados do PINTEC, de 2006-2008, revelam quatro obstáculos principais: elevados custos da inovação, riscos econômicos excessivos, escassez de fontes de financiamento; e falta de pessoal qualificado As empresas que não implementaram inovações e sem projetos relacionados $(58,8 \%$ do total), apontaram como principal barreira para inovar as condições de mercado (IBGE, 2010).

\section{Metodologia}

Quanto aos fins, a pesquisa caracteriza-se como exploratória, restringindo-se a definir objetivos e buscar mais informações sobre determinado assunto de estudo, realizando descrições da situação e descobrindo relações existentes entre os seus elementos (VERGARA, 2000). Quanto à natureza, a pesquisa é qualitativa, sendo aplicado o método de estudo de caso.

A pesquisa foi realizada em uma empresa de médio porte cearense de instalações industriais, de prestação de serviços, a qual se denominou XYZ, escolhida pelo fato de participar de uma associação voltada à gestão da inovação (Associação Gestinno).

Como primeiro passo do estudo foi realizada uma revisão de literatura por meio de levantamento bibliográfico em livros e artigos de periódicos, acerca da inovação em serviços, inovação organizacional, os fatores organizacionais internos favoráveis à inovação, assim como sobre as barreiras subjacentes. O objetivo desta revisão de literatura foi a constituição de uma lente ou perspectiva teórica para guiar a pesquisa (CRESWELL, 2010).

O levantamento dos artigos de periódicos foi realizado por meio do Portal Periódicos Capes. Seguiu-se os passos de revisão de literatura detalhado por Creswell (2010): identificação das 
palavras-chave; busca em livros e bancos de dados computadorizados; identificação da literatura últil; montagem do mapa de literatura; resumo dos artigos mais importantes; estruturação temática ou por conceitos importantes.

A revisão sobre os fatores organizacionais internos favoráveis a inovação foi realizado à luz do empreendedorismo corporativo, considerando que a configuração de uma organização empreendedora se distingue pela sua busca por inovação de produtos/serviços ou mercados como fonte de vantagem competitiva; da gestão do conhecimento, como fomentadora da geração de idéias inovadoras; da criatividade, tratada como fator-chave da inovação; da gestão de pessoas, no que diz respeito às práticas de RH voltadas para a inovação e do campo da inovação em si.

Foi realizado um corte nesse levantamento teórico, focando somente os fatores relacionados à estrutura, ambiente, processos e ferramentas, na perspectiva contextual da inovação (BESSANT; TIDD, 2009); e o papel de indivíduos-chave, na perspectiva individual (BESSANT; TIDD, 2009).

A partir dessa revisão de literatura, foi estruturada a coleta de dados quantitativa. $\mathrm{O}$ questionário abrangeu os seguintes componentes internos da organização inovadora: 1) papel da alta administração; 2) estrutura organizacional; 3) indivíduos-chave; 4) gestão de recursos humanos; 5) sistema de comunicação e informação; 6) aprendizagem com o ambiente.

Para cada um dos componentes acima citados, foram estabelecidas sentenças afirmativas. Os autores Terra (2005) e Tidd, Bessant e Pavit (2008) apresentam em suas obras modelos de sentenças que foram aproveitadas para o alcance dos objetivos deste estudo. O grau de ocorrência dessas sentenças foi analisado pelos respondentes por meio de uma escala Likert de 1 a 5 pontos: 1- muito baixo; 2-baixo; 3- médio; 4-alto; 5- muito alto. Após cada tópico dos componentes, foi colocado espaço para eventuais comentários dos respondentes.

Para a compreensão das barreiras à inovação, preferiu-se um enfoque mais indutivo, destacando da compreensão dos próprios participantes da pesquisa quais seriam essas barreiras, dado o contexto específico da empresa, atuante no ramo de prestação de serviços de instalações industriais. A literatura relacionada foi levantada apenas para dar base à explicação dos resultados encontrados, não sendo, por isso, realizada uma revisão de literatura exaustiva sobre o tema (CRESWELL, 2010).

O segundo passo da pesquisa consistiu na coleta de dados, com levantamento de informações no sítio da empresa na Internet; aplicação do questionário junto aos gestores de recursos humanos e gerente técnico, escolhidos por disponibilidade e conveniência; e entrevista estruturada, com questões abertas, com o gerente técnico, de recursos humanos, e o proprietário da empresa focando os objetivos e benefícios obtidos pela empresa na parceria com a Associação Gestinno. Também foram realizadas entrevistas não-estruturadas para esclarecimentos de dúvida junto aos gerentes. 
Todas as entrevistas foram gravadas, com tempo de duração de aproximadamente 20 minutos, para logo após, serem transcritas. Como terceira etapa, partiu-se para a análise dos dados, descrição e explicação dos resultados encontrados. Foi realizada a integração dos dados quantitativos e qualitativos para a interpretação e discussão dos resultados. Conforme explica Creswell (2010), apresentam-se primeiro os resultados quantitativos, seguidos das citações qualitativas que possam corroborar ou não os dados quantitativos.

\section{Apresentação e análise dos dados}

O objeto desta pesquisa foi uma empresa cearense de médio porte que conforme descrito pelos respondentes no questionário possui 200 funcionários e faturamento bruto acima de cinco milhões. A empresa possui 22 anos de existência, e atua com abrangência nacional, prestando serviços especializados de instalações e montagens industriais. A empresa tem como missão "Ser útil à indústria e comunidade" e como visão "Ser a melhor opção para clientes, colaboradores e sócios", como explicado pelos pesquisados. Também, segundo estes, os principais clientes externos da empresa são: Wartsila, Grendene, Santana Têxtil, TBM. Como fornecedores da empresa, foram destacados pelos respondentes: Wirex Cable, Sideraço, Trópico, Itaim, Carmehil, Meca Equipamentos Elétricos. O nível de concorrência que a empresa enfrenta foi considerado médio pelos pesquisados, sendo os principais concorrentes: MCM, Sert Engenharia, ENPECEL, ENIL. Como ação empreendida pela empresa para fomentar a inovação foi destacada a participação da Associação Gestinno como consultoria de inovação na empresa.

\subsection{Fatores internos favoráveis à inovação}

Com relação aos componentes internos da organização inovadora, foram encontrados os resultados que se seguem. Nos quadros a seguir, ler "GR" como gerente de recursos humanos e "GT" como gerente técnico.

Quanto ao componente "Papel da alta administração" (quadro 02), os gerentes técnicos e de recursos humanos concordaram entre si apenas no primeiro item: "a organização possui elevado nível de consenso sobre quais são os pontos fortes da empresa em termos de habilidades e competências". O gestor de RH justifica sua pontuação "baixo" aos itens 4 - "possui a dimensão "conhecimento" explícita e amplamente incorporada no planejamento estratégico da organização" e 5 - "adota um estilo de gestão que cria espaço e suporte dentro da organização para a geração de idéias inovadoras", afirmando que a dimensão conhecimento ainda está em processo de implementação, e que:

A empresa vem buscando fortemente a inovação, mas a cultura organizacional instalada não oferece suporte para a perpetuação de idéias e ações inovadoras, de forma que as 
equipes ainda trabalham de forma centralizadora, operacional, com subdivisão de tarefas e não de responsabilidades ou projetos.

Quadro 02 - Grau de ocorrência - Papel da Alta Administração

\begin{tabular}{|c|c|c|}
\hline PAPEL DA ALTA ADMINISTRAÇÃO & GR & GT \\
\hline $\begin{array}{l}\text { 1) ...possui elevado nível de consenso sobre quais são os pontos fortes da empresa em termos de } \\
\text { habilidades e competências. }\end{array}$ & Alto & Alto \\
\hline 2) ...comunica amplamente sua macroestratégia para todos os níveis organizacionais. & Médio & $\begin{array}{l}\text { Muito } \\
\text { Alto }\end{array}$ \\
\hline $\begin{array}{l}\text { 3) ...possui uma alta administração que estabelece frequentemente metas desafiadoras e um sentido } \\
\text { de urgência para a mudança da realidade em direção a uma visão estabelecida. }\end{array}$ & Médio & $\begin{array}{l}\text { Muito } \\
\text { Alto }\end{array}$ \\
\hline $\begin{array}{l}\text { 4) ....possui a dimensão "conhecimento" explícita e amplamente incorporada no planejamento } \\
\text { estratégico da organização }\end{array}$ & Baixo & Alto \\
\hline $\begin{array}{l}\text { 5) ...adota um estilo de gestão que cria espaço e suporte dentro da organização para a geração de } \\
\text { idéias inovadoras. }\end{array}$ & Baixo & $\begin{array}{l}\text { Muito } \\
\text { Alto }\end{array}$ \\
\hline
\end{tabular}

Fonte: Adaptado de Terra (2005) e Alpkan et al (2010).

Com relação ao item 5 - "adota um estilo de gestão que cria espaço e suporte dentro da organização para a geração de idéias inovadoras" (quadro 02), o gerente técnico enfatiza que os proprietários da empresa são os que possuem maior interesse em implementar ações inovadoras na organização, tendo tomado a iniciativa de formar a Associação Gestinno, junto a outros empresários, com o objetivo de implementar o "Programa de Gestão Integrada da Inovação Tecnológica em Micro e Pequenas Empresas" (Gestinno), criado pelo cubano Leonardo de la Rosa Marrero, doutor em Ciência Técnica na Rússia.

Sobre a Associação Gestinno, o proprietário da empresa afirmou que por meio dela objetiva alcançar a inovação na gestão. Quinzenalmente são feitas reuniões na associação, com participação dos representantes de todos os setores da empresa, inclusive dos proprietários. Nessas reuniões são realizadas atividades como: atualização do planejamento estratégico da empresa, definição dos projetos que a consultoria irá acompanhar e as metas do ano. Em uma quinzena é feita uma reunião de metas, e na outra, uma de projetos.

De acordo com o proprietário, os projetos que têm sido desenvolvidos junto à Gestinno são: qualidade, inovação, conhecimento, e inteligência corporativa. Os projetos são feitos por equipes. O projeto de inovação está em desenvolvimento. Em implementação está o Projeto "Inteligência corporativa", que tem como objetivo, conforme detalhado pelo gerente técnico, "sistematizar a captação das informações internas e externas, registrando, analisando e difundindo-as de forma informatizada e personalizada, utilizando-as como vantagem competitiva".

O projeto "Inteligência corporativa" está sendo concretizado por meio do sistema da TOTVS, com integração de todas as informações internas (permitindo, inclusive, o acompanhamento on-line da obra) e externas (relacionadas a clientes, fornecedores, concorrência, mercado). As informações internas já existiam, só precisavam ser sistematizadas, organizadas. As informações externas, agora é que estão sendo captadas, para alimentar o sistema. O gerente técnico 
enfatiza a importância da captação dessas informações, afirmando que a empresa tem dificuldades de pensar no futuro, sendo a análise de cenários um sonho ainda não realizado.

O projeto de Recursos Humanos (Conhecimento) está em desenvolvimento, sendo um dos seus objetivos fazer com que a força de conhecimento de cada colaborador, seja difundida e aprimorada. Uma das ações nesse sentido é documentar determinados procedimentos realizados pelos colaboradores, de forma que não apenas ele, mas outros também saibam realizá-los. Um segundo objetivo desse projeto, é trabalhar a questão da captação e manutenção da força de trabalho da empresa (gestão de talentos). Conforme o gerente técnico, a empresa tem dificuldades para reter a força de trabalho treinada pela própria empresa, que tem sido captada por empresas concorrentes.

Pelo exposto, pode-se afirmar que existe um suporte da alta administração da empresa para viabilizar a inovação. Conforme Alpkan et al (2010), o suporte da alta gestão se refere a disposição dos gestores para promover mecanismos de formalização e coordenação das sugestões individuais ou conjuntas, viabilizando os projetos inovadores e aumentando a eficiência organizacional. Porém, explica o gerente de RH que é necessário uma maior sensibilização das lideranças para a instauração de uma cultura inovadora em toda a empresa.

Quadro 03 - Grau de ocorrência - Estrutura organizacional

\begin{tabular}{|c|c|c|}
\hline ESTRUTURA ORGANIZACIONAL & GR & GT \\
\hline $\begin{array}{l}\text { 6) ...utiliza de forma constante de equipes multidisciplinares e formais que se sobrepõem à } \\
\text { estrutura formal tradicional e hierárquica }\end{array}$ & Baixo & $\begin{array}{l}\text { Não se } \\
\text { aplica }\end{array}$ \\
\hline $\begin{array}{l}\text { 7) ...faz uso constante de equipes temporárias, com grande autonomia, totalmente dedicadas a } \\
\text { projetos inovadores. }\end{array}$ & $\begin{array}{l}\text { Muito } \\
\text { baixo }\end{array}$ & $\begin{array}{l}\text { Não se } \\
\text { aplica }\end{array}$ \\
\hline $\begin{array}{l}\text { 8) ...com frequiência realiza pequenas reorganizações, de forma natural, para se adaptar às } \\
\text { demandas do ambiente competitivo. }\end{array}$ & Médio & $\begin{array}{c}\text { Muito } \\
\text { alto }\end{array}$ \\
\hline $\begin{array}{l}\text { 9) ...não permite que os empregados participem das decisões da empresa; elas são sempre } \\
\text { tomadas de cima para baixo. }\end{array}$ & Baixo & $\begin{array}{l}\text { Muito } \\
\text { baixo }\end{array}$ \\
\hline $\begin{array}{l}\text { 10)...permite que as decisões sejam tomadas no nível mais baixo possível. O processo decisório } \\
\text { é ágil; a burocracia é mínima. }\end{array}$ & Baixo & Médio \\
\hline 11)...possui muitas normas e regras rígidas & Baixo & Médio \\
\hline 12)...possui muitos níveis hierárquicos & Médio & Baixo \\
\hline $\begin{array}{l}\text { 13)...possui um sistema de trabalho onde as chefias definem as tarefas e os empregados as } \\
\text { executam }\end{array}$ & Alto & Médio \\
\hline $\begin{array}{l}\text { 14)...faz necessária a aprovação de vários níveis hierárquicos para que uma idéia nova seja } \\
\text { implementada. }\end{array}$ & Médio & $\begin{array}{l}\text { Muito } \\
\text { baixo }\end{array}$ \\
\hline $\begin{array}{l}\text { 15)...possui espaço de trabalho organizado de maneira a aumentar o contato interpessoal e a } \\
\text { favorecer o compartilhamento do conhecimento e de novas idéias entre os funcionários / } \\
\text { colaboradores da empresa. }\end{array}$ & $\begin{array}{l}\text { Muito } \\
\text { alto }\end{array}$ & Alto \\
\hline
\end{tabular}

Fonte: Adaptado de Terra (2005).

No componente "estrutura organizacional” (quadro 3), para o item 13 - "possui um sistema de trabalho onde as chefias definem as tarefas e os empregados as executam", o gerente técnico não o considerou alto como o gerente de RH, afirmando que "Depende da obra. Existem obras de pequeno porte, que não exigem a presença de um encarregado".

Ainda de acordo com o Quadro 3, o item 10 - "permite que as decisões sejam tomadas no nível mais baixo possível. O processo decisório é ágil; a burocracia é mínima" foi considerado de 
forma distinta pelos gestores pesquisados. O gerente técnico afirma que o proprietário da empresa não acompanha diretamente cada obra, mas indiretamente, por meio dos engenheiros que coordenam a obra, e dos gestores dos demais setores, em uma reunião mensal. Considera a gestão do processo decisório como participativa, sendo feita com base no "consenso", por meio de reuniões. Já o gestor de RH afirmou que os colaboradores não possuem autonomia para tomada de decisão, sem que antes, se reportem aos encarregados.

Quanto ao item 11 - "possui muitas normas e regras rígidas", foi considerado "médio" pelo gerente técnico, tendo em vista "que a execução dos projetos exige o atendimento de normas técnicas e legislação específicas", e "baixo" pelo gestor de recursos humanos. Quanto a "possui muitos níveis hierárquicos" o gerente técnico marcou a opção "baixo" e o de recursos humanos, a opção "médio", descrevendo este último, a estrutura da empresa da seguinte forma: na sede da empresa, existem as áreas de Recursos Humanos, Financeiro, Engenharia e Obras. Acima de todas essas áreas está a diretoria, composta pelos dois proprietários da empresa.

A estrutura de trabalho da obra é assim composta: encarregado ou coordenador da obra, que pode ser um engenheiro elétrico ou mecânico; profissionais da obra, que são os caldeireiros, serralheiros, soldadores, encanadores, eletricistas, instrumentistas, entre outros; os ajudantes dos profissionais, que dão suporte quanto a transporte de materiais, ferramentas, entre outros recursos necessários; e os meio-oficiais, que estão a caminho de se tornarem profissionais.

O item 14 - "faz necessária a aprovação de vários níveis hierárquicos para que uma idéia nova seja implementada" foi considerado "muito baixo" pelo gerente técnico e "médio" pelo gerente de recursos humanos. O gerente técnico cita o caso de um projeto implantado na empresa, denominado "Projeto Idéia", onde todos os funcionários podiam participar dando idéias de melhorias para as atividades da empresa (no escritório ou na obra), com brindes como incentivo. Apesar de não ter sido dado continuidade ao projeto, o gerente técnico afirma que a empresa é "muito aberta", pois todos os funcionários conseguem ter acesso direto à administração geral.

Além disso, a empresa faz reuniões trimestrais com todos colaboradores, onde discute sobre novas idéias e procura integrar o corpo funcional. Ainda segundo o gerente técnico, é feito esforço para a implementação das novas idéias que, porém, esbarram na própria falta de interesse e força de vontade dos funcionários para implementá-las. Sobre o assunto o gestor de RH faz referência ao fato da idéia não poder ser implementada de forma direta, sem antes ser discutida com os superiores.

Sobre os itens 6 e 7 (quadro 3), que se reportam ao uso de equipes multidisciplinares e temporárias, o gerente técnico afirmou que:

A empresa trabalha com equipes específicas. Quem trabalha com elétrica, trabalha somente na parte elétrica. Quem trabalha com mecânica, trabalha apenas na parte mecânica. [...] 
dentro da obra é muito difícil ter uma equipe multidisciplinar. Porém, as equipes dependem umas das outras para consolidarem o seu trabalho.

Também explica que no escritório, quando o cliente envia o projeto que deseja realizar para a empresa, o gerente técnico afirma que é em seu setor que o projeto é orçado em termos de materiais necessários e mão-de-obra. Não há o envolvimento de várias áreas para a definição desse orçamento, no máximo são levantadas informações sobre a mão-de-obra no setor de RH.

Quanto ao item 15 - "possui espaço de trabalho organizado de maneira a aumentar o contato interpessoal e a favorecer o compartilhamento do conhecimento e de novas idéias entre os funcionários da empresa" (Quadro 3), o gestor de RH afirmou que:

A empresa possui um espaço de trabalho que facilita o trabalho em equipe e é aberto a mudanças. Porém ainda não existe uma cultura de incorporação das inovações, do trabalho multidisciplinar, da importância da autonomia no trabalho, etc.

Os resultados acima descritos permitem constatar que a estrutura organizacional da empresa não é muito rígida em termos de normas e regras, nem possui excessiva hierarquização, que impeçam a agilidade do processo decisório e a realização de reorganizações necessárias para acompanhar as demandas do ambiente competitivo. Apesar da autonomia limitada dada aos colaboradores, a empresa é aberta à recepção de novas idéias, precisando, porém, elaborar mecanismos formais e contínuos para geri-las.

Com relação à existência de equipes totalmente dedicadas a projetos inovadores, não considerada pelos respondentes, pode-se discordar dessa opinião, tendo em vista o envolvimento de representantes de cada setor em equipes de projetos junto à Associação Gestinno, voltados para a inovação das práticas de gestão.

Quadro 04 - Grau de ocorrência - Indivíduos-chave

\begin{tabular}{|c|c|c|}
\hline INDIVÍDUOS-CHAVE & GR & GT \\
\hline $\begin{array}{l}\text { 16) ...possui colaboradores com competência técnica para dar suporte ao desenvolvimento das } \\
\text { idéias inovadoras, capazes de compreender a tecnologia nova a ser adotada. }\end{array}$ & Médio & Alto \\
\hline $\begin{array}{l}\text { 17)...possui colaboradores, que além da competência técnica, possuem inspiração para a resolução } \\
\text { de problemas técnicos aparentemente insolúveis. }\end{array}$ & Baixo & Médio \\
\hline $\begin{array}{l}\text { 18)...possui colaboradores que são dotados de poder e influência na organização para levar à } \\
\text { frente as idéias inovadoras, removendo os obstáculos do caminho. }\end{array}$ & Baixo & $\begin{array}{l}\text { Muito } \\
\text { Baixo }\end{array}$ \\
\hline $\begin{array}{l}\text { 19)....possui colaboradores que atuam como gatekeepers (indivíduos que coletam informações de } \\
\text { várias fontes e que as repassa para as pessoas mais capacitadas ou interessadas em usá-las). }\end{array}$ & Baixo & Baixo \\
\hline
\end{tabular}

Fonte: Adaptado de Tidd, Bessant e Pavit (2008).

No componente "indivíduos-chave" (quadro 04), acerca do item 16 - "possui colaboradores com competência técnica para dar suporte ao desenvolvimento das idéias inovadoras, capazes de compreender a tecnologia nova a ser adotada", o gestor técnico deu pontuação "alta". Para justificar essa sua resposta, ele cita o exemplo recente em que a empresa teve que, pela primeira vez, efetuar instalações em uma termoelétrica, e os colaboradores atuaram com sucesso na execução do projeto. 
O gestor técnico explica ainda que quando chega um equipamento novo, como uma "unidade de força", geralmente vem acompanhado de instruções em DVD. Ressalta, porém, que: “os colaboradores-chave estão envolvidos com os processos do dia-a-dia, mas não há ainda uma cultura estabelecida entre os funcionários para a busca de idéias inovadoras".

A empresa, portanto, é possuidora de colaboradores cuja competência técnica permite o enfrentamento de novos desafios, porém, ainda não sensibilizados para empreender energia voltada para a inovação. Os indivíduos-chave, considerados por Tidd, Bessant e Pavitt (2008), são aqueles preparados para levar a inovação com entusiasmo, com fôlego e capacidade para resolver problemas (defensores técnicos), ou aqueles cuja forte influência consegue abrir os caminhos para viabilizar a implementação de uma idéia inovadora (patrocinadores), entre outras formas de atuação.

Quadro 5 - Grau de ocorrência - Gestão de Recursos Humanos

\begin{tabular}{|c|c|}
\hline GESTÃO DE RECURSOS HUMANOS & GR \\
\hline 20) .... possui processo de seleção focado em atrair as melhores pessoas em termos de potencial inerente & Alto \\
\hline $\begin{array}{l}\text { 21) ...tem uma sistema de contratação que prima pela diversidade de perfis, com o fim de aumentar a } \\
\text { criatividade e a capacidade de aprendizado da organização. }\end{array}$ & Alto \\
\hline $\begin{array}{l}\text { 22) ...possui um processo de contratação fundamentado nas competências essenciais necessárias ao } \\
\text { negócio. }\end{array}$ & Médio \\
\hline $\begin{array}{l}\text { 23) ...possui um processo de seleção que avalia a capacidade do indivíduo em colaborar e trabalhar em } \\
\text { equipe }\end{array}$ & Alto \\
\hline 24)... promove o desenvolvimento de carreira, com ênfase nas promoções & $\begin{array}{l}\text { Muito } \\
\text { baixo }\end{array}$ \\
\hline $\begin{array}{l}\text { 25)...adota um planejamento de carreira que busca dotar os funcionários de diferentes perspectivas e } \\
\text { experiências }\end{array}$ & $\begin{array}{l}\text { Muito } \\
\text { baixo }\end{array}$ \\
\hline 26) ... realiza atividades que favorecem a sociabilização entre os trabalhadores & Alto \\
\hline $\begin{array}{l}\text { 27).... avalia a capacidade e o comportamento inovador, reconhecidos e premiados no corpo funcional por } \\
\text { meio de incentivos financeiros e/ou não financeiros. }\end{array}$ & Baixo \\
\hline 28)... associa a evolução dos salários, principalmente à aquisição de competências e não ao cargo ocupado & $\begin{array}{l}\text { Muito } \\
\text { baixo }\end{array}$ \\
\hline $\begin{array}{l}\text { 29)... aplica práticas de remuneração/recompensa relacionadas ao desempenho da equipe (e não apenas ao } \\
\text { desempenho individual) }\end{array}$ & Médio \\
\hline 30)... avalia a capacidade dos funcionários em trabalhar com os outros, na avaliação de desempenho & Alto \\
\hline 31)...compartilhamento de conhecimento é um dos critérios da avaliação de desempenho & Baixo \\
\hline 32)...aplica avaliação de desempenho baseada na performance do time & Baixo \\
\hline 33)... concede feedback aos colaboradores com relação à avaliação de desempenho & Médio \\
\hline $\begin{array}{l}\text { 34)...realiza um elevado investimento e incentivo ao treinamento e desenvolvimento profissional e pessoal } \\
\text { dos empregados }\end{array}$ & Alto \\
\hline 35)... realiza treinamentos sobre trabalho em equipes & Alto \\
\hline 36)... realiza treinamentos sobre relações interpessoais & Alto \\
\hline 37)...realiza atividades de mentoria e tutoria & Baixo \\
\hline 38)...possui estratégias explícitas e bem articuladas para retenção de ta & Baixo \\
\hline
\end{tabular}

Fonte: Adaptado da literatura pesquisada.

Sobre o componente "gestão de recursos humanos", o gerente de RH fez o seguinte comentário:

A Gestão de Recursos Humanos vem buscando implantar novos métodos de gestão das pessoas, com base em competências, tornando as mesmas identificáveis e claras, para se realizar um plano de carreira e de pessoas eficiente. Mas ainda está em processo de implantação, não havendo ainda um plano de avaliação de desempenho eficiente, ou de competência bem implantado, assim como não há plano de carreira. 
Os resultados do quadro 5 demonstram que a empresa se preocupa em atrair as pessoas com os melhores potenciais, e que possuam as competências necessárias para o negócio, o que favorece o conhecimento interno segundo Lopes-Cabrales et al (2009). Com um sistema de contratação que favorece a diversidade de perfis, a empresa contribui para a formação de um ambiente criativo, conforme abordagem de Terra (2005), onde pessoas com diferentes formações e experiências trazem novas perspectivas para a solução de problemas. Os processos de seleção, avaliação de desempenho, de remuneração e de treinamentos voltados para o trabalho em equipe, assim como as atividades de sociabilização, realizados pela empresa pesquisada, são fatores que tem associação positiva e significante com a atividade de inovação, de acordo com Lopes-Cabrales et al (2009).

Quadro 6 - Grau de ocorrência - Sistemas de informação e comunicação

\begin{tabular}{|c|c|c|}
\hline SISTEMAS DE INFORMAÇÃO E COMUNICAÇÃO & GR & GT \\
\hline $\begin{array}{l}\text { 39)...possui uma comunicação eficiente em todos os sentidos (de cima para baixo, de baixo para } \\
\text { cima e entre áreas distintas }\end{array}$ & Baixo & Médio \\
\hline $\begin{array}{l}\text { 40)...proporciona amplo acesso das informações para todos os funcionários, à base de dados e } \\
\text { conhecimento da organização }\end{array}$ & Médio & $\begin{array}{c}\text { Muito } \\
\text { alto }\end{array}$ \\
\hline $\begin{array}{l}\text { 41)...possui grande disciplina, eficiência e incentivo para a documentação do conhecimento e } \\
\text { know-how existente na empresa }\end{array}$ & Baixo & Médio \\
\hline $\begin{array}{l}\text { 42)...possui um sistema de acesso e compartilhamento de informações bastante amigável (fácil de } \\
\text { aprender e usar) }\end{array}$ & Baixo & $\begin{array}{c}\text { Muito } \\
\text { alto }\end{array}$ \\
\hline $\begin{array}{l}\text { 43)...tem as suas informações bem organizadas segundo um sistema de classificação que faz } \\
\text { sentido aos usuários }\end{array}$ & Baixo & $\begin{array}{c}\text { Muito } \\
\text { alto }\end{array}$ \\
\hline $\begin{array}{l}\text { 44)...as informações mais relevantes estão codificadas e organizadas em espaços virtuais/banco de } \\
\text { dados de acesso geral (e não no computador de indivíduos ou áreas bem específicas da organização. }\end{array}$ & Baixo & $\begin{array}{c}\text { Muito } \\
\text { alto }\end{array}$ \\
\hline $\begin{array}{l}\text { 45)...os resultados da empresa são amplamente divulgados internamente e servem como fonte de } \\
\text { aprendizado para ações gerenciais }\end{array}$ & Alto & $\begin{array}{c}\text { Muito } \\
\text { alto }\end{array}$ \\
\hline
\end{tabular}

Fonte: Adaptado de Terra (2005).

Sobre o item 45 - "os resultados da empresa são amplamente divulgados internamente e servem como fonte de aprendizado para ações gerenciais", do componente "sistemas de informação e comunicação" (quadro 6), o gerente técnico comentou que são feitas reuniões mensais, chamadas reuniões de indicadores, onde são apresentados e discutidos os resultados dos indicadores de desempenho por obra (por exemplo, indicador de despesas da obra, de andamento da obra, entre outros). Semanalmente, são feitas reuniões de cronograma da obra, para acompanhar se está havendo atraso ou não. A empresa também utiliza um sistema Kanban para controle das atividades rotineiras, sendo estudada a inclusão de controle de projetos e metas nesse sistema.

Já o item 44 - "as informações mais relevantes estão codificadas e organizadas em espaços virtuais/banco de dados de acesso geral (e não no computador de indivíduos ou áreas bem específicas da organização)" foi considerado "muito alto" pelo gerente técnico e "baixo" pelo gestor de RH, que assim o considerou, tendo em vista o sistema de informação se encontrar em processo de implantação. Quanto ao fato das informações estarem bem organizadas, o gerente técnico citou o seguinte exemplo: 
O proprietário da empresa me passou um e-mail [...], pedindo um projeto da adutora da Ambev, que foi executada em 1998, [...] foi encontrado sem demora". [...] a própria Ambev não tem mais em mãos esse documento.

De acordo com os resultados do quadro 6, e depoimentos dos gestores, percebe-se que a empresa está sendo cuidadosa para desenvolver uma melhor competência relacionada à implementação de um sistema de informação e comunicação mais adequado. Conforme estudos de Antoncic (2007), Christensen (2005), Terra (2005), e Barbieri et al (2004) esse componente pode ser considerado elemento essencial para a inovação, levando a organização a desenvolver uma inteligência competitiva mais apurada, rápida e criativa na tomada de decisão.

Quadro 07 - Grau de ocorrência - Aprendizado com o meio ambiente

\begin{tabular}{|c|c|c|}
\hline APRENDIZADO COM O MEIO AMBIENTE & GR & GT \\
\hline $\begin{array}{l}\text { 46)...aprende muito com os seus clientes. Existem vários mecanismos formais e informais bem } \\
\text { estabelecidos para essa finalidade. }\end{array}$ & Alto & Alto \\
\hline 47)...tem habilidade na gestão de parcerias com outras empresas & Baixo & Baixo \\
\hline 48)...tem habilidade na gestão de parcerias com Universidades e Institutos de Pesquisa & $\begin{array}{l}\text { Muito } \\
\text { baixo }\end{array}$ & Baixo \\
\hline $\begin{array}{l}\text { 49)...toma decisão de alianças sempre relacionada a decisões estratégicas e de aprendizado } \\
\text { importantes. Os funcionários da empresa percebem, muito claramente, esse objetivo de } \\
\text { aprendizado. }\end{array}$ & $\begin{array}{l}\text { Muito } \\
\text { baixo }\end{array}$ & Baixo \\
\hline 50)...sabe operar em rede e aprender com os seus fornecedores & Médio & Médio \\
\hline 51)...há um esforço sistemático de benchmarking e inteligênc & Baixo & Médio \\
\hline
\end{tabular}

Fonte: Adaptado de Terra (2005).

$\mathrm{Na}$ análise do componente "aprendizado com o meio ambiente" (Quadro 7), o gestor técnico e de RH consideram "alto" o item 46 - "aprende muito com os seus clientes. Existem vários mecanismos formais e informais bem estabelecidos para essa finalidade". Sobre este item, comenta o gestor técnico que a empresa tem aprendido muito em termos de peculiaridades no atendimento aos clientes. Cada cliente exige um tratamento específico, sendo criado um indicador de "como lidar com os clientes".

Acerca do item 48 - "tem habilidade na gestão de parcerias com Universidades e Institutos de Pesquisa", afirmou o gerente técnico que a empresa tem planos de fazer parcerias com as universidades e centros de pesquisa, focando os projetos de montagem da indústria.

Já o item 50 - "sabe operar em rede e aprender com os seus fornecedores" foi considerado "médio" por ambos os gestores. O gestor técnico considerou o item 51 - "há um esforço sistemático de benchmarking e inteligência competitiva" como "médio", diferentemente do gestor de RH que o considerou "baixo". O gerente técnico afirma que a empresa tem uma boa relação com os fornecedores, existindo aqueles que são "chave" para a empresa, como os fornecedores de cabo, pois existem projetos onde os cabos representam 50\% do seu orçamento; assim como os de equipamentos, que oferecem apoio no repasse das informações sobre o uso de instrumentos com nova tecnologia. 
De acordo com Terra (2005), é dos clientes que se originam a maior parte das idéias inovadoras. Estar sintonizado, desse modo, com as suas necessidades, é competência essencial para a inovação, sendo fator favorável para a empresa analisada. Também, manter um bom relacionamento com os fornecedores facilita a realização de atividades de aprendizado e inovação conjuntas.

\subsection{Barreiras à atividade inovativa}

A partir do estudo realizado, e tendo como base a revisão de literatura, foi possível levantar as seguintes barreiras à atividade inovativa, que se caracterizam como desafios a serem enfrentados pela empresa em sua busca pela inovação: 1) Falta de um processo de inovação sistemático; 2) Perdas de informação de mercado, sobre tecnologias, e de possibilidades com parceiros externos: a empresa não possui um setor comercial ou de marketing, tendo dificuldade para captação de clientes e análise de cenários. Não tem realizado esforços no estabelecimento de parcerias com outras empresas, assim como com Universidades e institutos de pesquisa; 3) Perda de pessoal qualificado; 4) Problemas para manter pessoal qualificado; 5) Resistência dos empregados à mudança; 6) Falta de uma abordagem sistêmica da inovação: não existe uma cultura organizacional voltada para a inovação; não são aplicadas práticas de compensação pelas iniciativas inovadoras; falta de um plano de desenvolvimento de carreira; e inexistência de uma gestão sistemática das novas idéias.

\section{Considerações Finais}

O estudo fez uso da estratégia de estudo de caso para responder sua problemática e objetivos. O objetivo geral da pesquisa foi caracterizar o processo de inovação numa empresa prestadora de serviços de instalações industriais. Para tanto, analisou-se os fatores internos favoráveis à inovação, assim como as barreiras internas e externas, buscando ao final, identificar a forma básica de inovação predominante na empresa.

Sobre a existência de fatores internos favoráveis à inovação na organização analisada, foi utilizado o raciocínio dedutivo e indutivo, integrando as informações quantitativas e qualitativas nos resultados. As informações qualitativas serviram tanto para reforçar os resultados quantitativos, como para esclarecê-los. Para a identificação das barreiras à inovação na empresa, utilizou-se o método indutivo de pesquisa. A partir da interpretação desses resultados, buscou-se responder a problemática do estudo.

Respondendo o primeiro objetivo específico do estudo, foram identificados os seguintes fatores internos favoráveis à inovação da prestadora de serviços de instalações industriais:

- apoio da alta administração; 
- estrutura organizacional simples, com normas e regras não muito rígidas, pequeno grau de hierarquização, presença de equipes de projetos voltados para a inovação e acesso facilitado à alta administração;

- gestão participativa, aberta para a recepção de novas idéias, com processo decisório baseado no consenso;

- espaço de trabalho favorável ao clima criativo;

- colaboradores com competência técnica para enfrentar situações novas e/ou adversas;

- processos de seleção e recrutamento com foco na atração de pessoas detentoras das competências necessárias ao negócio e capacidade de aprender;

- sistema de contratação com foco na diversidade de perfis;

- práticas de RH que favorecem o trabalho em equipe;

- cuidado para a implementação de um sistema de informação e comunicação mais adequados, com foco na melhoria da inteligência competitiva;

- e existência de mecanismos formais e informais para fomentar o aprendizado com clientes e fornecedores.

Atendendo ao segundo objetivo específico desta pesquisa constatou-se como barreiras internas à inovação, problemas na estrutura e processos da empresa, relacionados à falta de órgãos responsáveis pelas atividades comerciais e de marketing; problemas processuais na área de recursos humanos, relacionados a manutenção dos talentos da empresa, e ao envolvimento dos colaboradores e lideranças na busca pela inovação. Como consequência dessas dificuldades, constatou-se como barreiras externas à inovação na empresa, a perda de informação de mercado e de possibilidades com parceiros externos.

Em resposta ao terceiro objetivo específico deste estudo, verificou-se que a empresa analisada busca a inovação organizacional, com foco nos processos de gestão, realizada em conjunção com uma inovação tecnológica, por meio da implementação de um sistema de informação.

Respondendo à problemática do estudo, constatou-se que o processo de inovação na organização prestadora de serviços pesquisada está mais relacionado à inovação gerencial. A imprevisibilidade das relações entre os atores e beneficiários no setor de serviços, exige desses atores diferentes conhecimentos e competências que devem ser melhor gerenciados, o que pode justificar o maior interesse da empresa pela inovação organizacional.

Nesse processo de implementação da inovação, a empresa tem diante de si o desafio de tornar a abordagem de inovação mais sistêmica, não apenas envolvendo as lideranças em torno de valores e objetivos comuns de inovação, mas também incentivando-os a disseminá-los para toda 
organização, com o fim de estabelecer uma cultura organizacional inovadora. Além disso, criar processos sistemáticos e ferramentas para viabilizar e dar suporte à criação de idéias, assim como alinhar melhor as estratégias de recursos humanos em torno dos objetivos de inovação.

Para estudos posteriores, sugere-se a ampliação do escopo de pesquisados, abrangendo uma amostra significativa de empresas de médio e grande porte, para a compreensão da forma de inovação predominante em setores específicos de serviço, e que permita o uso da estatística multivariada. Sugere-se ainda a inclusão de variáveis relacionadas ao comportamento organizacional e a fatores ambientais, como a cultura local e as pressões do consumidores.

\begin{abstract}
This article sought to characterize the process of innovation in in medium sized enterprises of services, in Northeast Brazil, identifying, from this analysis, the existence of internal factors conducive to innovation, possible barriers to innovative activity, and the type of innovation implemented. After a theoretical review on innovation in services, factors conducive to innovation and its barriers, the authors conducted an exploratory study, qualitative, using the case study method. The research was conducted in a medium sized enterprises of industrial facilities located in Fortaleza, Ceará, Brazil. In the results, we found a predominance of organizational innovation. As main barriers to innovative activity, we identified: 1) issues of a systemic nature: lack of a systematic innovation process lack of scenario analysis, loss of potential partnerships with other companies and research institutions, and difficulty in attracting customers; 2) people management: lack of recognition of the human factor in the innovation process, because the organizational culture is not focused on innovation; loss of qualified staff. As favorable internal factors to innovation were identified: support from top management; simple and flexible organizational structure; favorable workspace to creative climate; technical competence of employees; selection processes aligned to the promotion of creativity; ability to learn and diversity profiles; existence of formal and informal mechanisms to promote learning with customers and suppliers. The culture of innovation is not consolidated, but is in the process of being implemented because the company is linked to an association of development of innovation (GESTINNO).
\end{abstract}

Key-words: organizational innovation; favorable factors of innovation; barriers to innovation.

\title{
Referências
}

ALPKAN, L. et al Organizational support for intrapreneurship and its interaction with human capital to enhance innovative performance. Management decision, v. 48, n. 5, p. 732-755, 2010.

ANTONCIC, B.. Intrapreneurship: a comparative structural equation modeling study. Industrial management \& data systems, v. 107, n. 3, p. 309-325, 2007.

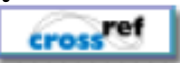

BARBIERI, J. Cs. Organizações inovadoras. 2. ed. São Paulo: FGV, 2004.

BESSANT, J.; TIDD, J. Inovação e empreendedorismo. Porto Alegre: Bookman, 2009.

BREM, A. The boundaries of innovation and entrepreneurship: conceptual background and essays on selected theoretical and empirical aspects. Germain: Gabler, 2008.

CHRISTENSEN, K. S. Enabling intrapreneurship: the case of a knowledge-intensive industrial company. European Journal of Innovation Management., v. 8, n. 3, p. 305-322, 2005. 
FREEMAN C.; SOETE L. A economia da inovação industrial. Campinas: Unicamp, 2008.

GALLOUJ, Faïz. Innovation in the service economy. Great Britain: Edward Elgar Publishing, 2002.

GALLOUJ, Faïz; WEINSTEIN, Olivier. Innovation in services. Research Policy, v. 26, n.4-5, p. 537-556, 1997.

$$
\text { cross ref }
$$

GADREY J., GALLOUJ, F., WEINSTEIN O., New modes of innovation: how services benefit industry, International Journal of Service Industry Management, v. 6, n. 3, p.4-16, 1995.

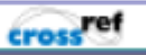

HAMEL, G. The why, what and how of management innovation. Harvard Business Review, p.72-84, fev. 2006.

HORNSBY J. S.; KURATKO, D. F.; NAFFZIGER D. W.; MONTAGNO R. V. An interactive model of the corporate entrepreneurship process. Baylor University, 1993.

IBGE: Instituto Brasileiro de Geografia e Estatística. Pesquisa de inovação tecnológica: 2008. Rio de Janeiro : IBGE, 2010.

INÁCIO JÚNIOR, E. Padrões de inovação em pequenas e médias empresas e suas implicações para o desempenho inovativo e organizacional. 2008. 272f. Tese (Doutorado em Política Ccientífica e Tecnológica) - Universidade Estadual de Campinas, Campinas, 2008.

JOHNSON, D. What is innovation and entrepreneurship?. Industrial and commercial training, v.33, n.4, p. 135-140, 2001.

cross ref

KNOX, S. The boardroom agenda: developing the innovative organization. Corporate Governance, v. 2, n. 1, p. 27 36, 2002.

cross ref

KURATKO, D.F.; MONTAGNO, R.V.; HORNSBY, J.S. Developing an intrapreneurial assessment instrument for an effective corporate entrepreneurial environment, Strategic management journal, v.11, n. 1, p. 49-58, 1990.

LOEWE, Pierre; DOMINIQUINI, Jennifer. Overcoming the barriers to effective innovation, Strategy \& leadership, v.34, n. 1, p. 24-31, 2006.

\section{cross ref}

LOPES-CABRALES, A.; PÉREZ-LUÑO, A.; CABRERA, R. V.. Knowledge as a mediator between HRM practices and innovative activity. Human resource management, v. 48, n. 4, p. 485- 503, jul.-ago. 2009.

MADRID-GUIJARRO, A.; GARCIA, D.; VAN AUKEN, H. Barriers to innovation among Spanish Manufacturing SMEs. Journal of Small Business Management, v. 47, n.4, p. 465-488, 2009.

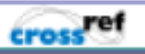

MATTAR, F. N. Pesquisa de marketing: metodologia, planejamento, execução, análise. 5. ed. São Paulo: Atlas, 1999.

MENDEL, N. M. F. Estratégia empresarial e inovação organizacional: um estudo de caso na Brasil Telecom. $110 f$. 2004. Dissertação (Mestrado em Administração e negócios) - Pontifícia Universidade Católica, Rio Grande do Sul, 2004.

OECD-Eurostat. Oslo Manual: Guidelines for Collecting and Interpreting Innovation Data. 3. ed. 2005. Disponível em: <ftp://ftp.cordis.lu/pub/eims/docs/eims full text 98 191.pdf>. Acesso em: 15 mar. 2011.

PERIS-ORTIZ, M.. An analytical model for human resource management as an enabler of organizational renewal: a framework for corporate entrepreneurship. International entrepreneurship and management journal., v.5, n.4, p.461-479, 2009. 
PETERS, B. Innovation and firm performance: an empirical investigation for German Firms. Germany: PhysicaVerlag HD, 2008.

PRAHALAD, C. K.; KRISHNAN, M.S. A nova era da inovação: a inovação focada no relacionamento com o cliente. Rio de Janeiro: Elsevier, 2008.

PUFFAL, D. P.; COSTA, A. B. A interação universidade-empresa e a inovação: resenha de estudos e a situação Brasileira. In: SIMPÓSIO DE GESTÃO DA INOVAÇÃO TECNOLÓGICA, 25., 2008, Brasília. Anais... Brasília: ANPAD, 2008, 1 CD-ROM.

SANTOS, D. F. L.. A influência da inovação no desempenho das firmas no Brasil. 315f. 2009. Dissertação (Mestrado em Administração de Empresas) - Universidade Presbiteriana Mackenzie, São Paulo, 2009.

SCHUMPETER, J.A. Teoria do Desenvolvimento Econômico: uma investigação sobre lucros, capital, crédito, juro e o ciclo econômico. 3.ed. São Paulo: Nova Cultural, 1988.

SECITECE - SECRETARIA DA CIÊNCIA, TECNOLOGIA E EDUCAÇÃO SUPERIOR DO ESTADO DO CEARÁ. Apresentação. Disponível em: 〈http://www.sct.ce.gov.br/institucional/ historico〉. Acesso em: 22 jan. 2011. a.

SECITEC - CT \& Inovação. Disponível em: <http://www.sct.ce.gov.br/categoria1>. Acesso em: 22 jan. 2011. b.

TERRA, J.C.C.. Gestão do conhecimento: o grande desafio empresarial. 5. ed. Rio de Janeiro: Elsevier, 2005.

TETHER, Bruce S.; TAJAR, Abdelouahid. The organisational-cooperation mode of innovation and its prominence amongst european service firms. Research policy, v. 37, n.4, p.720-739, 2008.

\section{cross $5^{\text {ref }}$}

TIDD, J.; BESSANT, J.; PAVITT, K. Gestão da Inovação. São Paulo: Bookman, 2008.

VAN DE VEN, A. H.; ANGLE, H. L.; POOLE, M. S. Research on the Management of Innovation: the Minnesota studies. Oxford University Press, 2000.

VAN DER AA, W.; ELFRING, T. Realizing innovation in services. Scandinavian Journal of Management, v.18, n.2, p. 155-171, 2002.

cross ref

VERGARA, S. C.. Projetos e relatórios de pesquisa em administração. São Paulo: Atlas, 2000.

\section{Dados dos autores:}

\section{Nome completo: Vivianne Pereira Salas Roldan}

Filiação institucional: Universidade Federal do Ceará

Departamento: Instituto Universidade Virtual - Curso de Administração (Bacharelado)

Função ou cargo ocupado: Professor - Tutor à distância

Endereço completo para correspondência: Av. da Universidade, 2486 - Benfica. Fortaleza-Ce.

Brasil. CEP: 60020-180.

Telefones para contato: (85) 3366-7788.

e-mail:vsalasroldan@gmail.com

Nome completo: Augusto Cézar de Aquino Cabral

Filiação institucional: Universidade Federal do Ceará 
Departamento: Programa de Pós-Graduação em Administração e Controladoria

Função ou cargo ocupado: Professor

Endereço completo para correspondência: Av. da Universidade, 2486 - Benfica. Fortaleza-Ce.

Brasil. CEP: 60020-180.

Telefones para contato: (85) 3366-7788.

e-mail: cabral@ufc.br

Nome completo: José Carlos Lázaro da Silva Filho

Filiação institucional: Universidade Federal do Ceará

Departamento: Programa de Pós-Graduação em Administração e Controladoria

Função ou cargo ocupado: Professor

Endereço completo para correspondência: Av. da Universidade, 2486 - Benfica. Fortaleza-Ce.

Brasil. CEP: 60020-180.

Telefones para contato: (85) 3366-7788.

e-mail: silvafilhode@yahoo.com.br

Nome completo: Sandra Maria dos Santos

Filiação institucional: Universidade Federal do Ceará

Departamento: Programa de Pós-Graduação em Administração e Controladoria

Função ou cargo ocupado: Professor

Endereço completo para correspondência: Av. da Universidade, 2486 - Benfica. Fortaleza-Ce.

Brasil. CEP: 60020-180.

Telefones para contato: (85) 3366-7788.

e-mail:smsantosufc@gmail.com

Nome completo: Maria Naiula Monteiro Pessoa

Filiação institucional: Universidade Federal do Ceará

Departamento: Programa de Pós-Graduação em Administração e Controladoria

Função ou cargo ocupado: Professor

Endereço completo para correspondência: Av. da Universidade, 2486 - Benfica. Fortaleza-Ce.

Brasil. CEP: 60020-180.

Telefones para contato: (85) 3366-7788.

e-mail:naiula@ufc.br

Enviado em: 15/01/2012

Aprovado em: 28/01/2013 